\title{
Moyamoya disease associated with ankylosing spondylitis in a 9-year-old child: a case report
}

\author{
Fan Yang, Peicong Ge and Xun Ye
}

\begin{abstract}
Background: Ankylosing spondylitis was reported to associate with an increased risk of cerebrovascular diseases. In this article, we aimed to report the first case of ankylosing spondylitis associated with moyamoya disease treated with encephalo-duroarterio-synangiosis.

Case presentation: A 9-year-old boy with ankylosing spondylitis appeared a symptom of repeated transient ischemic attacks which performed as left hemiparesis. Magnetic resonance angiography showed a typical finding of left anterior cerebral artery, bilateral middle cerebral arteries and the supraclinoid portion of the right internal carotid artery stenosis with an abnormal vascular network at the base of the brain, diagnosed with moyamoya disease. He received a medication treatment but did not underwent revascularization surgery. After three months, ankylosing spondylitis symptoms got some relief, whereas transient ischemic attacks was more frequency. Due to the bad cerebral blood flow on acetazolamide computed tomography perfusion and poor clinical manifestation, he underwent a right encephalo-duroarterio-synangiosis. Postoperatively, the symptoms of transient ischemic attacks disappeared.
\end{abstract}

Conclusions: We reported the first case of ankylosing spondylitis associated with moyamoya disease. Moyamoya disease could appear in patients with ankylosing spondylitis. Revascularization surgery probably is an effective treatment for preventing preoperative ischemic events recurrence.

Keywords: Ankylosing spondylitis, Moyamoya disease, Transient ischemic attack

\section{Background}

Ankylosing spondylitis (AS) is an autoimmune disease caused by systemic inflammation, predominantly involves the axial skeleton [1]. AS was reported to have an increased risk of cerebrovascular diseases [2-4]. However, there was no report that AS was associated with moyamoya disease (MMD). And we aimed to report the first case of ankylosing spondylitis associated with moyamoya disease treated with encephalo-duroarterio-synangiosis (EDAS).

\footnotetext{
* Correspondence: yexun79@hotmail.com

Department of Neurosurgery, Beijing Tiantan Hospital, Capital Medical University; China National Clinical Research Center for Neurological Diseases; Center of Stroke, Beijing Institute for Brain Disorders, Beijing Key Laboratory of Translational Medicine for Cerebrovascular Disease, 6 Tiantanxili, DongCheng District, Beijing 100050, China
}

\section{Case presentation}

A 9-year-old boy suffered a severe transient ischemic attacks (TIA) performed as left hemiparesis. He admitted to Beijing Tiantan hospital in July 2015. At age 7, he had a left-side weakness for a period of time, which did not arouse the attention of his parents. From the age 8 , he appeared low back pain for more than three months and suffered a morning back stiffness lasted more than thirty minutes which diminished with activity and returned after rest. His grandfather, father and uncle all diagnosed AS. However, both of his body and neurological examinations revealed no positive performance.

The patient's cerebral magnetic resonance imaging (MRI) was normal (Fig. 1). Magnetic resonance angiography (MRA) showed artery stenosis of the left anterior cerebral artery, bilateral middle cerebral arteries and the supraclinoid portion of the right internal carotid artery. What's more, the blood supply of bilateral cerebral hemispheres 


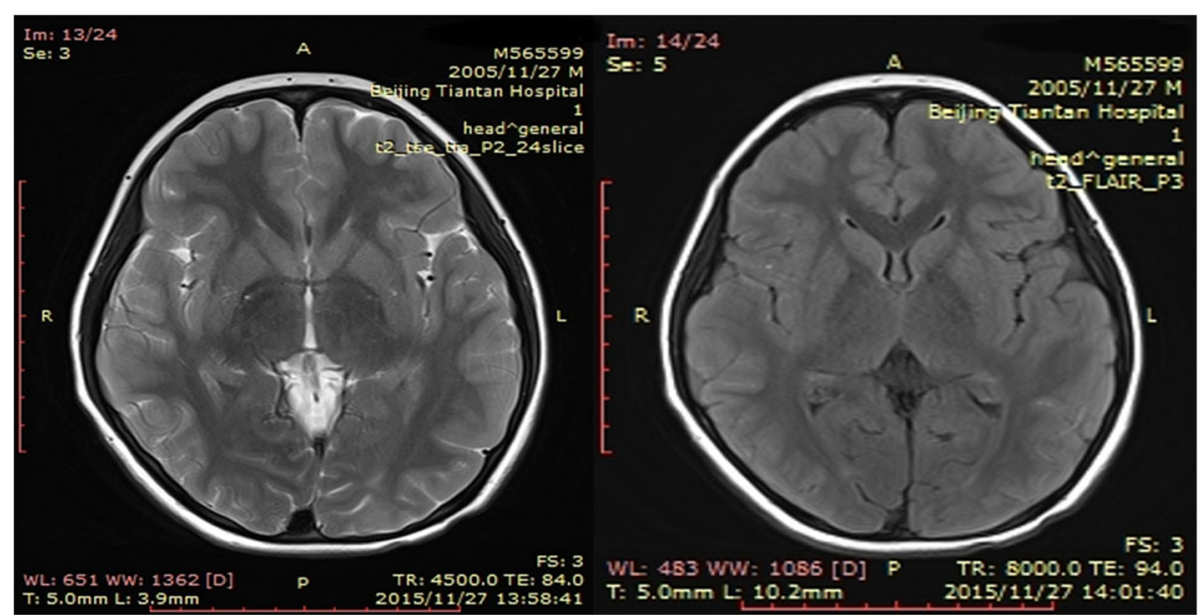

Fig. 1 Axial T2-weighted and T2- Flair MRI Showing normal

was primarily by the posterior circulation and abnormal compensatory vascular appeared at the base of the brain. So this patient diagnosed with moyamoya disease (Fig. 2). Cerebral blood flow on acetazolamide computed tomography perfusion revealed decreased perfusion in bilateral frontal regions (Fig. 3).

Because the patient had low back pain and morning back stiffness and a positive family history for AS. Auxiliary examinations related to AS were taken. The patient's HLA-B27 was positive, C-reactive protein concentration was $0.715 \mathrm{mg} / \mathrm{dl}$ which was higher than normal $(0-0.4 \mathrm{mg} /$ dl). And the patient's erythrocyte sedimentation rate (ESR) increased to $8 \mathrm{~mm} / \mathrm{h}$. Serum antinuclear antibody (ANA) and rheumatoid factor (RA) test were negative. Other serum chemical tests of AS were taken and all in the normal limits. Anteroposterior and posteroanterior pelvic radiographs show early erosive changes in the left iliac bone (arrow) that could be interpreted as grade 2 sacroiliitis. The right sacroiliac joint is normal (Fig. 4). The patient was diagnosed AS according to the criteria for ankylosing spondylitis [5]. As for treatment, the patient received oral indometacin $25 \mathrm{mg}$ three times a day but did not underwent revascularization surgery.

Three months later, low back pain and morning back stiffness got some relief, whereas TIA was more frequency. Therefore, he underwent a right EDAS in November 2015. After ten-month follow-up, no further TIAs appeared, the patient underwent a CTA examination at follow-up time, there were a lot of compensatory vascular created and the CTP shows the perfusion of the bilateral cerebral hemisphere improved a lot. And the symptoms of AS was well controlled by medication.

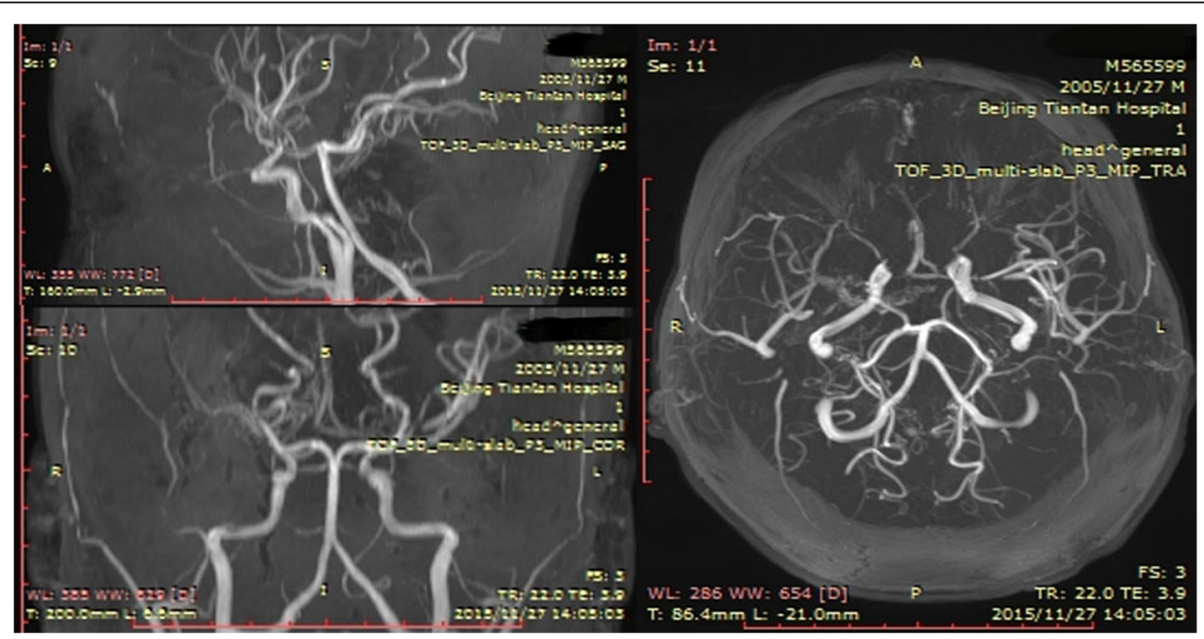

Fig. 2 MR angiography showing left anterior cerebral artery, both middle cerebral arteries and the supraclinoid portion of the right internal carotid artery, with both cerebral hemispheres primarily supplied by the posterior circulation 


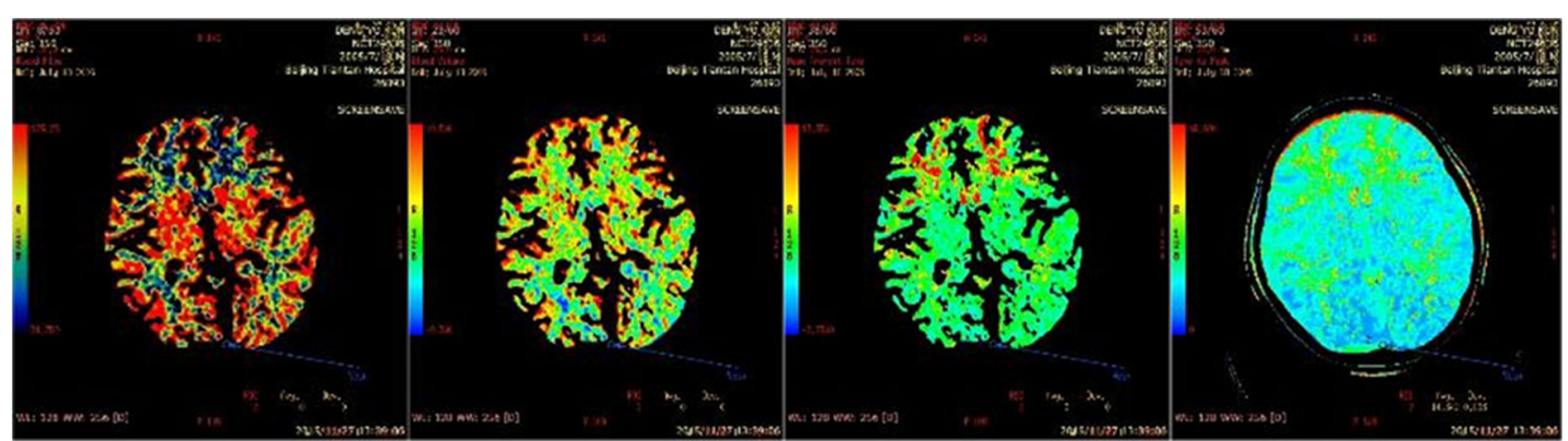

Fig. 3 CT perfusion (CTP) shows hypoperfusion in the bilateral frontal area, and increased mean transit time (MTT) and time to peak (TTP)

\section{Discussion}

Ankylosing spondylitis is a common autoimmune disease caused by inflammatory rheumatic. The population morbidity ranging between 0.1 and $1.4 \%$ [6, 7]. There is accumulating evidence that patients with AS suffer from an increased ischemic stroke risk, in comparison with the general population [2-4]. Compared to patients without AS, the AS patients got a 2.20 times risk for ischemic stroke [3].

The reason why AS association a high risk of ischemic stroke remains unclear. But inflammatory processes seems played an important role in AS development. What's more, the influence of inflammation in atherogenesis and plaque formation had been reported yet [8]. Lange $\mathrm{U}$ et al. had found that, AS patients' blood inflammatory markers were much higher compared with patients without AS, such as interleukin 6, tumor necrosis factor alpha, and Creactive protein [9]. In addition, in other literatures, AS patients were more likely to associated with early features of atherosclerosis, such as the thickness of intima media of the carotid arteries increased and flow-mediated dilatation of the brachial arteries impaired [10, 11]. Therefore, the atherogenesis and plaque formation caused by systemic inflammation may be the reason for higher risk of ischemic stroke in the AS patients.

Moyamoya disease is a cerebrovascular disease characterized by a progressive occlusion of the internal carotid artery or its terminal branches [12]. The pathogenesis of moyamoya disease remains unclear. Suzuki and Takaku suspected that the autoimmune played an important role in MMD [13]. Recently, more and more reports have showed the association between moyamoya and other autoimmune diseases, including Graves disease, Type 1 diabetes mellitus, systemic lupus erythematosus and Behcet's disease [14, 15]. Review of the literatures reveals no report for MMD associate with AS. In our study, we think the autoimmune may play an important role in these two diseases. On the one hands, the autoimmune may be the reason for higher risk of ischemic stroke in the AS patients. On the other hands, although the

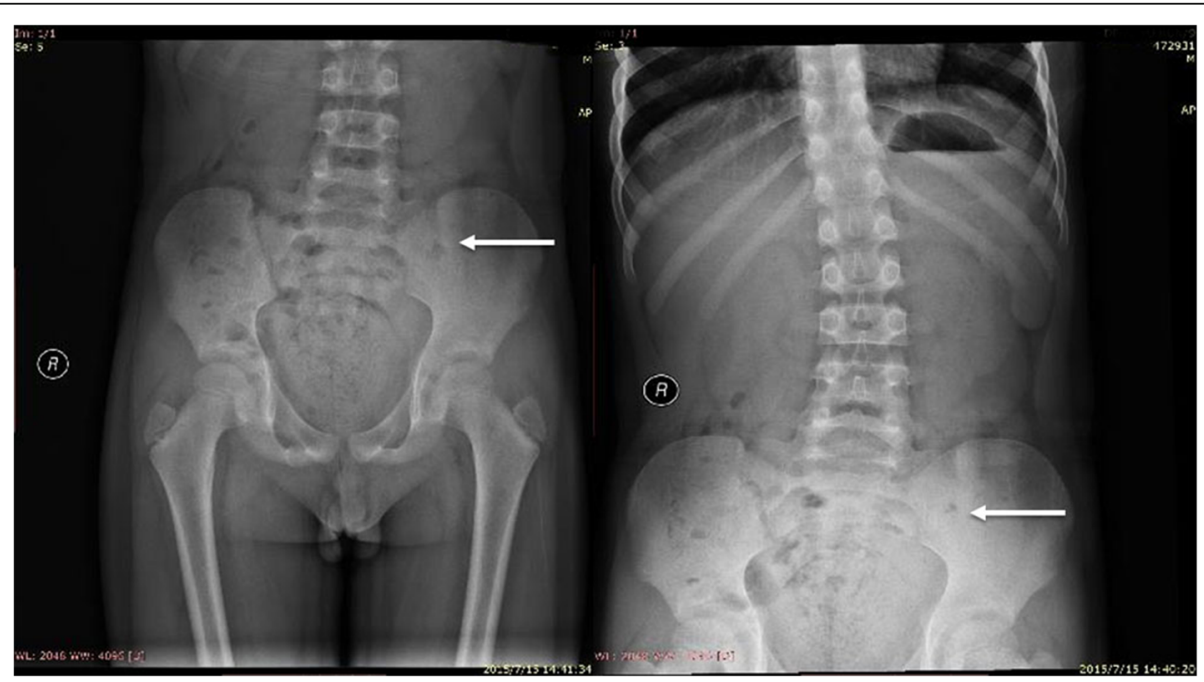

Fig. 4 Anteroposterior and posteroanterior pelvic radiographs show early erosive changes in the left iliac bone (arrow) that could be interpreted as grade 2 sacroiliitis. The right sacroiliac joint is normal 
mechanism of MMD was unclear, autoimmune probably was the most important mechanism for the pathogenesis of MMD. The patient in our study had typical moyamoya vessels and AS symptoms and diagnosed for both MMD and AS. The stenosis for this patient may cause by accelerated atherosclerosis which resulted from the same autoimmune mechanisms with the AS. Therefore, MRA, CTA or DSA needs to be done if AS patients suffer cerebrovascular events.

According to the guidelines of AS management issued by international experts, NSAIDs, including selective inhibitors of cyclooxygenase 2 , are the first-line drug for the pain and stiffness treatment [5]. In our patient, he received NSAID treatment about three months, low back pain and morning back stiffness got some relief, whereas TIA was more frequency. Therefore, he underwent a right EDAS and had no further TIAs. EDAS may have a role for prevention of TIA in AS patients with moyamoya disease. However, longer follow-up should be taken to evaluate the long-term effects of EDAS in patient with MMD and AS.

\section{Conclusion}

We have reported a rare case of MMD associated with AS in a 9-year-old child. In this case report, we emphasized that MRA, CTA or DSA are important for diagnosis if AS patients suffered cerebrovascular events, and EDAS probably is an effective treatment for preventing preoperative ischemic events recurrence.

\section{Abbreviations}

ANA: Antinuclear antibody; AS: Ankylosing spondylitis; EDAS: Encephaloduroarterio-synangiosis; ESR: Erythrocyte sedimentation rate; MMD: Moyamoya disease; MRA: Magnetic resonance angiography; MRI: Magnetic resonance imaging; RA: Rheumatoid factor; TIA: Transient ischemic attacks

\section{Acknowledgments}

Not applicable.

\section{Funding}

Not applicable.

Availability of data and materials

Not applicable.

\section{Authors' contributions}

FY and PG acquired the data, analyzed the data and wrote the manuscript $X Y$ interpreted the data. All of the authors critically revised the manuscript, read and approved the final manuscript.

\section{Competing interests}

The authors declare that they have no competing interests.

\section{Consent for publication}

Written informed consent was obtained from the patient's parents for publication of this case report and accompanying images.

Ethics approval and consent to participate Not applicable.
Received: 5 May 2017 Accepted: 1 June 2017

Published online: 06 July 2017

\section{References}

1. Braun J, Sieper J. Ankylosing spondylitis. Lancet. 2007;369(9570):1379-90.

2. Han C, Robinson DW Jr, Hackett MV, Paramore LC, Fraeman KH, Bala MV. Cardiovascular disease and risk factors in patients with rheumatoid arthritis, psoriatic arthritis, and ankylosing spondylitis. J Rheumatol. 2006;33(11):2167-72.

3. Lin CW, Huang YP, Chiu YH, Ho YT, Pan SL. Increased risk of ischemic stroke in young patients with ankylosing spondylitis: a population-based longitudinal follow-up study. PLoS One. 2014;9(4):e94027.

4. Szabo SM, Levy AR, Rao SR, Kirbach SE, Lacaille D, Cifaldi M. Increased risk of cardiovascular and cerebrovascular diseases in individuals with ankylosing spondylitis: a population-based study. Arthritis Rheum. 2011;63(11):3294-304.

5. Taurog JD, Chhabra A, Colbert RA. Ankylosing Spondylitis and axial Spondyloarthritis. N Engl J Med. 2016;374(26):2563-74.

6. Braun J, Bollow M, Remlinger G, Eggens U, Rudwaleit M, Distler A, et al. Prevalence of spondylarthropathies in HLA-B27 positive and negative blood donors. Arthritis Rheum. 1998;41(1):58-67.

7. Gran JT, Husby G. The epidemiology of ankylosing spondylitis. Semin Arthritis Rheum. 1993;22(5):319-34.

8. Sherer $Y$, Shoenfeld $Y$. Mechanisms of disease: atherosclerosis in autoimmune diseases. Nat Clin Pract Rheumatol. 2006;2(2):99-106.

9. Lange U, Teichmann J, Stracke H. Correlation between plasma TNF-alpha, IGF-1, biochemical markers of bone metabolism, markers of inflammation/ disease activity, and clinical manifestations in ankylosing spondylitis. Eur J Med Res. 2000;5(12):507-11.

10. Cece H, Yazgan P, Karakas E, Karakas O, Demirkol A, Toru I, et al. Carotid intima-media thickness and paraoxonase activity in patients with ankylosing spondylitis. Clin Invest Med. 2011;34(4):E225.

11. Sari I, Okan T, Akar S, Cece H, Altay C, Secil M, et al. Impaired endothelial function in patients with ankylosing spondylitis. Rheumatology (Oxford). 2006:45(3):283-6.

12. Suzuki J, Kodama N. Moyamoya disease-a review. Stroke. 1983;14(1):104-9.

13. Suzuki J, Takaku A. Cerebrovascular "moyamoya" disease. Disease showing abnormal net-like vessels in base of brain. Arch Neurol. 1969;20(3):288-99.

14. Bower RS, Mallory GW, Nwojo M, Kudva YC, Flemming KD, Meyer FB. Moyamoya disease in a primarily white, midwestern US population: increased prevalence of autoimmune disease. Stroke. 2013:44(7):1997-9.

15. Chen JB, Liu Y, Zhou LX, Sun H, He M, You C. Increased prevalence of autoimmune disease in patients with unilateral compared with bilateral moyamoya disease. J Neurosurg. 2016;124(5):1215-20.
Submit your next manuscript to BioMed Central and we will help you at every step:

- We accept pre-submission inquiries

- Our selector tool helps you to find the most relevant journal

- We provide round the clock customer support

- Convenient online submission

- Thorough peer review

- Inclusion in PubMed and all major indexing services

- Maximum visibility for your research

Submit your manuscript at www.biomedcentral.com/submit
C BioMed Central 